\title{
A novel control strategy for power quality improvement in grid- connected solar photovoltaic system
}

\author{
Pankaj Gakhar, Manoj Gupta \\ Department of Electrical Engineering, Poornima University, India
}

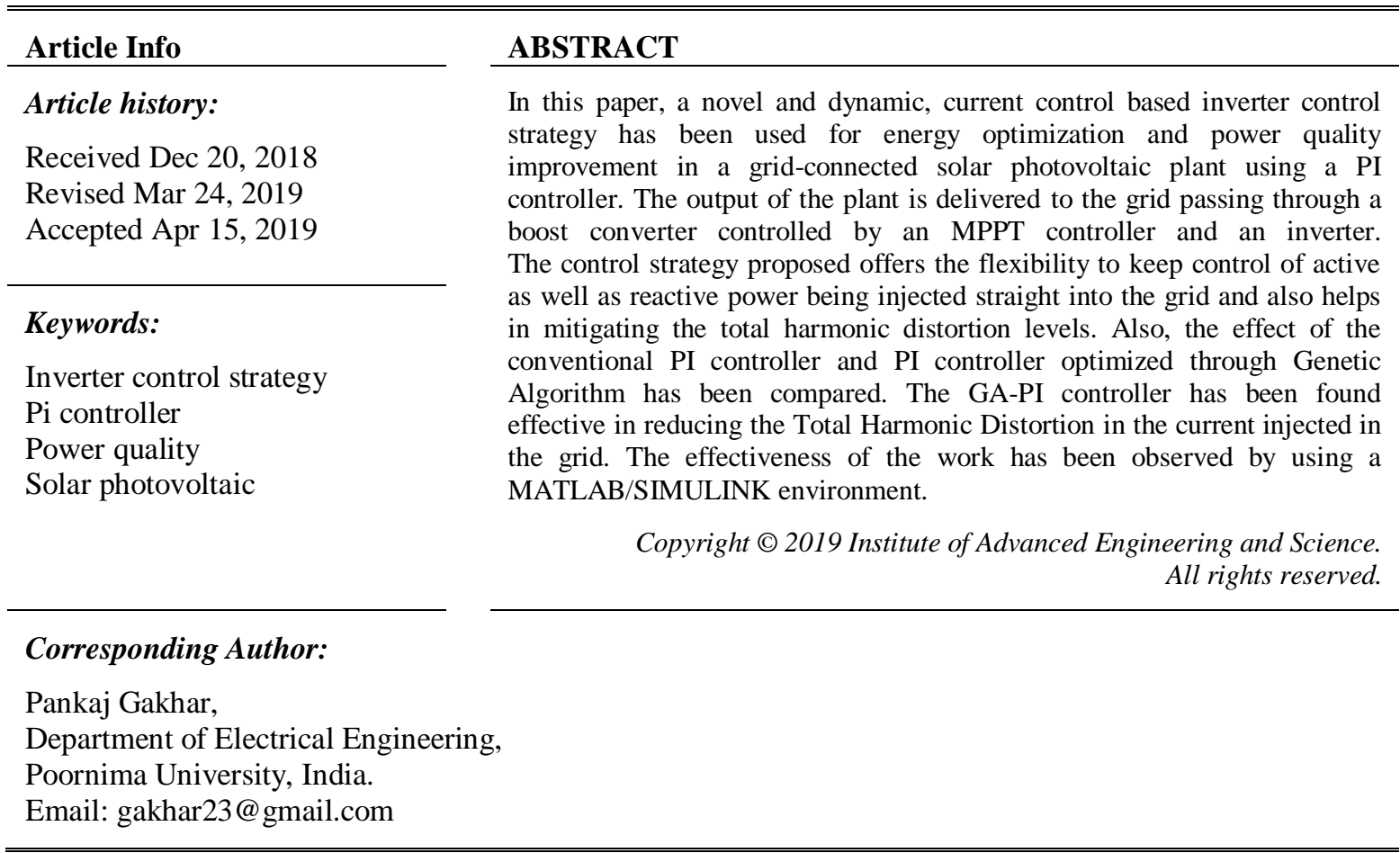

\section{INTRODUCTION}

Due to the rapid increase in the demand for electric power in the last decade, and the depleting fossil fuels in nature, there is a need for an alternative source of energy for generating electric power. Under such circumstances, energy generation from solar photovoltaic is one of the most suitable solutions available today. Since the energy generated is one of the cleanest and pollution-free source of energy and its availability in abundance has increased the use of solar photovoltaic increased by a substantial amount. In the remote areas, the use of standalone solar photovoltaic is an expensive proposition because of the high installation cost of batteries. So in order to reduce the cost of power generation, it is more economical to inject the electric power to the grid.

In systems designed for injecting the electric power generated from solar photovoltaic into the grid, various power electronic converters are used to convert the electric power into suitable form for the grid. This power electronic device usually works on high switching frequencies and also degrades the quality of electric power. The output of the inverter comprises of the harmonics components along with the fundamental component. Hence, it is very important to maintain the power quality especially total harmonic distortion in the range as per IEEE standards [1-3].

In grid applications, the boost converter is utilized for elevating the levels of output voltage, mainly because of the low voltage at output of the PV array. These boost converters use the high switching duty cycle for achieving higher voltages as they are not compatible for applications where high power is involved. In most of the grid-connected solar PV systems, cascaded boost converters are used for providing the high voltage gains. But this also has a drawback of increased complexity of the control circuit and a substantial increase in cost. Also the higher losses due to cascading of boost converters results in lower efficiency [4]. It has been seen in the literature that the use of transformer less topology in the grid-connected applications 
has proved to provide higher efficiency and voltage gains. So, multilevel converters are used in gridconnected systems [5-6].

PI controllers have been used by the researchers from last many years in the grid-connected solar photovoltaic applications for controlling the parameters because of the robustness, simple design and good performance. In this paper, a control strategy with a PI controller for the grid-connected solar photovoltaic system has been presented for total harmonic distortion reduction and control of power delivered to the grid.

\section{MODELING OF 100KW GRID CONNECTED SOLAR PHOTOVOLTAIC SYSTEM}

A grid linked solar photovoltaic system is a form of electric system which usually converts the energy from solar radiation into electric power and after that exchanges it furthermore in the suitable form expected. As the Solar photovoltaic system is normally linked to the grid, it has got the liberty to switch spare energy within the main grid after nurturing any local need of energy. Although whenever the system produces energy much less as compared to which is needed to assist the localized requirements than spare energy is utilized right from the main grid. Therefore, photovoltaic energy system linked to grid functions as a great alternative source of electric power. The photovoltaic or PV system is engineered to switch electric power coming from photovoltaic systems towards the main grid.

Initially, a dc voltage boost converter is utilized to boost the output voltage of the PV array to a level as per the requirement of the grid voltage [7]. The dc boost converter takes to care for achieving the point of maximum power extraction from the PV module and in order to extract the maximum power, there are various algorithms available such as Perturb and Observe, Incremental Conductance, Hill Climbing etc. [8]. Then a PWM based inverter is utilized to convert the dc output of boost converter into sinusoidal ac form as per grid frequency and voltage levels. The output of the inverter is a square waveform. A basic layout of grid linked solar photovoltaic system as shown in Figure 1.

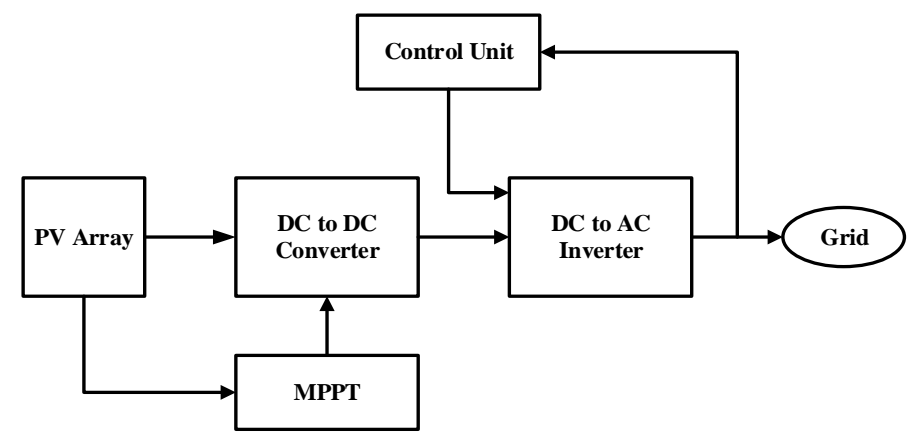

Figure 1. A basic layout of grid linked solar photovoltaic system

A model for100KW photovoltaic grid-connected system has been designed in MATLAB SIMULINK environment.

\subsection{Solar PV Array Modeling}

The solar PV array has been designed to deliver maximum $100 \mathrm{KW}$ of power to the grid. For the purpose, 330 solar panels have been connected (5 in series, 66 in parallel). The design consideration of the solar PV array is mentioned in the Table1:

Table1. PV Array Specifications

\begin{tabular}{ccc}
\hline S. No. & Parameter & Description \\
\hline 1 & PV panel make & Sun Power SPR 305-E \\
2 & Maximum power per panel & $305.226 \mathrm{~W}$ \\
3 & Voc & $64.2 \mathrm{~V}$ \\
4 & Isc & $5.96 \mathrm{~A}$ \\
5 & Vmp & $54.7 \mathrm{~V}$ \\
6 & Imp & $5.58 \mathrm{~A}$ \\
7 & Cells per module & 96 \\
\hline
\end{tabular}




\subsection{DC/DC Voltage Converter}

The voltage received as an output of the solar array varies due to change in solar irradiation and also due to the functioning of the MPPT unit. But, this varying voltage cannot be provided to the inverter. The inverter needs a constant input dc voltage for proper functioning, so here a boost converter is used which converts the varying dc voltage into fix dc output voltage. Here, the boost converter which is designed converts the varying voltage to a fix $1450 \mathrm{dc}$ voltage[9-10]. The method of preferring the voltage levels of the DC bus is explained through the equations below. The line to line grid voltage (r.m.s value) is considered to be approx. $415 \mathrm{~V}$. So enough DC Link voltage is required to ensure the AC output. So the DC link voltage level is calculated as:

$$
V_{D C}=\frac{\sqrt{2} V_{L-L(R M S)}}{m \sqrt{3}}
$$

Here, the voltage level of the DC Link is selected as $1450 \mathrm{~V}$. The value of boost converter inductor is given by:

$$
L_{B o o s t}=\frac{V_{S}\left(V_{D C}-V_{S}\right)}{\Delta I_{L} f_{S} V_{D C}}
$$

Here,

$V_{S}=$ Source Voltage.

$V_{D C}=$ Output DC Voltage.

$f_{S}=$ Switching frequency of the switch used in the boost converter.

$\Delta I_{L}=$ Ripple current.

$$
\Delta I_{L}=.1 * \mathrm{I}_{O U T} \frac{V_{O U T}}{V_{S}}
$$
is given by:

The PV Array is coupled with the system with the help of a capacitor. The value of the capacitor

$$
C=\frac{P_{P V}}{2 \omega V_{c} u}
$$

Here,

PPV $=$ Power of solar array.

$\mathrm{u}=$ amplitude value of voltage ripple

$V_{c}=$ Mean Voltage.

$\omega=$ Angular frequency.

The duty cycle of the boost converter is given by

$$
D=1-\frac{V_{P V}}{V_{D C}}
$$

DC-DC converter parameters as shown in Table 2. The values of the parameters calculated using the above formulations are as follows:

\begin{tabular}{ccc}
\multicolumn{3}{c}{ Table 2. DC-DC Converter Parameters } \\
\hline S.No & Parameter & Value \\
\hline 1 & Duty Cycle, D & 0.81 \\
2 & Input voltage, $\mathrm{V}_{\mathrm{S}}$ & $273.5 \mathrm{~V}$ \\
3 & DC Link Voltage, $\mathrm{V}_{\mathrm{OUT}}$ & $1450 \mathrm{~V}$ \\
4 & Switching Frequency, & $5 \mathrm{KHz}$ \\
5 & $\mathrm{C}_{\mathrm{DC} \text { LINK }}$ & $1580 \mu \mathrm{f}$ \\
6 & Inductor, $\mathrm{L}$ & $2.3 \mathrm{mH}$ \\
7 & Capacitor, $\mathrm{C}_{\mathrm{PV}}$ & $0.7 \mu \mathrm{f}$ \\
\hline
\end{tabular}

\subsection{MPPT Controller}

It is the unit that functions for extracting maximum electric power from PV array and provides itto the inverter. The solar array current and voltage parameters are dependent on solar irradiation which is 
uncertain in nature throughout any day. So, here MPPT plays its role. It simply modifies the duty cycle of the switch in the boost converter [11]. Certainly, there are numerous methods for maximum power point. Here, Perturb and Observe method has been employed for extracting maximum electric power from PV array.

\subsection{Inverter Control Strategy}

In the inverter control strategy, the inverter converts the dc power to ac power using a control mechanism [12-13]. Majorly the control mechanism for the inverter is based on the combination of certain cascaded loops. Some of them are as follows:

a) Outer loop intended for power and Internal loop intended for current

b) Outer loop intended for DC Link voltage and internal loop intended for current

c) Outer loop intended for voltage and internal loop intended for power.

In the literature, the outer loop intended for DC Link voltage and internal loop intended for current type is the most commonly used loop structure. The DC Link Voltage management loop balances the electric power flow in the system whereas the current management loop deals with the power quality maintenance and mitigation of harmonics present in the current so that it could be injected to grid.

\subsubsection{Controller for Real and Reactive Power}

When it comes to any grid-connected inverter system the active as well as reactive power can easily be managed by the power controller. There are two approaches available for controlling active and reactive power for the Voltage Source Converter system. The first approach is voltage mode controlled which is basically employed in substantial power applications like FACTS controllers. The active as well as the reactive power, both are handled by managing the phase angle along with the amplitude of inverter voltage comparative to point of common coupling voltage(PCC).

Another strategy for controlling active and reactive power is current mode regulation. With this approach, the current in the line is regulated simply by a concentrated strategy and the active and reactive power are managed by taking care of phase angle along with amplitude of inverter output current. Another advantage of this mode of control is that it is protected against over currents [14-15]. Schematic diagram of an inverter control strategy as shown in Figure 2.

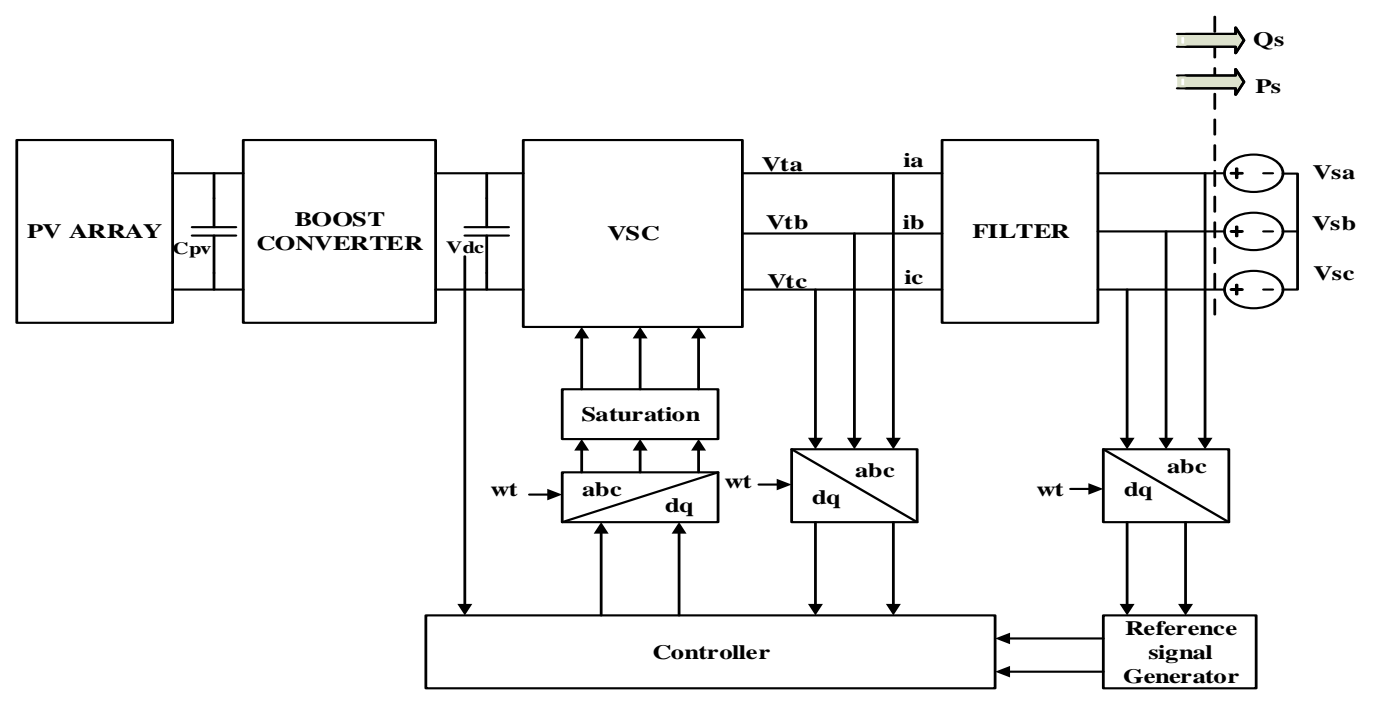

Figure 2. Schematic diagram of an inverter control strategy

\subsubsection{Modeling of Controller}

Let us assume the AC system voltages are given by:

$$
V_{s a}(t)=V_{s} \cos \left(\omega_{0} t+\theta_{0}\right)
$$

Where,

$V_{s}=$ Amplitude of line to neutral voltage

$\omega_{0}=$ Angular frequency

$\theta_{0}=$ Phase angle 
The state space equivalent is given by

$V_{s}(t)=V_{s} e^{j\left(\omega_{0} t+\theta_{0}\right)}$

The dynamics of the AC side of the inverter can be described by following state space phasor

$\frac{L d i}{d t}=-\left(R+r_{o n}\right) i+V_{t}-V_{s}$

By substituting Vs from the above equation we get,

$\frac{L d i}{d t}=-\left(R+r_{o n}\right) i+V_{t}-V_{s} e^{j\left(\omega_{0} t+\theta_{0}\right)}$

Now, by substituting $i=i_{d q} e^{j \rho}$ and $V_{t}=V_{t d q} e^{j \rho}$ in the above equation, we get

$\frac{L d\left(i_{d q} e^{j \rho}\right)}{d t}=-\left(R+r_{o n}\right)\left(i_{d q} e^{j \rho}\right)+\left(V_{t d q} e^{j \rho}\right)-V_{s} e^{j\left(\omega_{0} t+\theta_{0}\right)}$

Where, $f_{d q}=f_{d}+j f_{q}$ and the above equation is rewritten as

$L \frac{d\left(i_{d q}\right)}{d t}=-j L \frac{d \rho\left(i_{d q}\right)}{d t}-\left(R+r_{o n}\right)\left(i_{d q}\right)+\left(V_{t d q}\right)-V_{s} e^{j\left(\omega_{0} t+\theta_{0}-\rho\right)}$

Now, by decomposing above equation we get,

$$
\begin{aligned}
& L \frac{d\left(i_{d}\right)}{d t}=L \frac{d \rho}{d t} i_{q}-\left(R+r_{o n}\right)\left(i_{d}\right)+\left(V_{t d}\right)-V_{s} \cos \left(\omega_{0} t+\theta_{0}-\rho\right) \\
& L \frac{d\left(i_{q}\right)}{d t}=L \frac{d \rho}{d t} i_{d}-\left(R+r_{o n}\right)\left(i_{q}\right)+\left(V_{t q}\right)-V_{s} \sin \left(\omega_{0} t+\theta_{0}-\rho\right)
\end{aligned}
$$

These above two equations are not in standard state space form. Thus, we introduce new variable $\omega$, where $\omega=\frac{d \rho}{d t}$ which gives

$$
\begin{aligned}
& L \frac{d\left(i_{d}\right)}{d t}=L \omega(t) i_{q}-\left(R+r_{o n}\right)\left(i_{d}\right)+\left(V_{t d}\right)-V_{s} \cos \left(\omega_{0} t+\theta_{0}-\rho\right) \\
& L \frac{d\left(i_{q}\right)}{d t}=L \omega(t) i_{d}-\left(R+r_{o n}\right)\left(i_{q}\right)+\left(V_{t q}\right)-V_{s} \sin \left(\omega_{0} t+\theta_{0}-\rho\right) \\
& L \frac{d\left(i_{d}\right)}{d t}=-\left(R+r_{o n}\right)\left(i_{d}\right)+\left(V_{t d}\right)-V_{s} \cos \left(\omega_{0} t+\theta_{0}\right) \\
& L \frac{d\left(i_{q}\right)}{d t}=-\left(R+r_{o n}\right)\left(i_{q}\right)+\left(V_{t q}\right)-V_{s} \sin \left(\omega_{0} t+\theta_{0}\right)
\end{aligned}
$$

Let us assume $\omega(t)=0$, then

\subsubsection{Current Mode Control of Active/Reactive Power Controller} given by:

The active as well as reactive power is given to the AC system at the point of common coupling is

$$
\begin{aligned}
& P_{s}(t)=\frac{3}{2}\left[V_{s d}(t) i_{d}(t)+V_{s q}(t) i_{q}(t)\right] \\
& Q_{s}(t)=\frac{3}{2}\left[-V_{s d}(t) i_{q}(t)+V_{s q}(t) i_{d}(t)\right]
\end{aligned}
$$

Where $V_{s d}$ and $V_{s q}$ are voltage components in the d-q frame and also it must be noted that these components cannot be varied or controlled in a steady state. Therefore the active and reactive power can get managed by $i_{d}$ and $i_{q}$ respectively. If the control system is capable of providing fast reference tracking then active and reactive power can be controlled by separate reference values which are given by the following equations: 


$$
\begin{aligned}
& i_{\text {dref }}(t)=\frac{2}{3 V_{s d}} P_{\text {sref }}(t) \\
& i_{\text {qref }}(t)=-\frac{2}{3 V_{s d}} Q_{\text {sref }}(t)
\end{aligned}
$$

Inverter Control: Let us assume a steady state operation and by replacing $\omega(t)$ by $\omega_{0}$, we deduce that,

$L \frac{d\left(i_{d}\right)}{d t}=L \omega_{0} i_{q}-\left(R+r_{o n}\right)\left(i_{d}\right)+\left(V_{t d}\right)-V_{s d}$

$L \frac{d\left(i_{q}\right)}{d t}=L \omega_{0} i_{d}-\left(R+r_{o n}\right)\left(i_{q}\right)+\left(V_{t q}\right)-V_{s q}$

Where

$$
\begin{aligned}
& V_{t d}=\frac{V_{D C}}{2} m_{d}(t) \\
& V_{t q}=\frac{V_{D C}}{2} m_{q}(t)
\end{aligned}
$$

Now here $m_{d}$ and $m_{q}$ are given by

$$
\begin{aligned}
& m_{d}=\frac{2}{V_{D C}}\left(u_{d}+L \omega_{0} i_{q}+V_{s d}\right) \\
& m_{q}=\frac{2}{V_{D C}}\left(u_{q}+L \omega_{0} i_{d}+V_{s q}\right)
\end{aligned}
$$

Where $u_{d}$ and $u_{q}$ are two new input for control.

\subsection{PI Controller}

The Proportional Integral (PI) controllers are the most commonly and widely used controllers in the field of the control system. Such type of controller comprises of a proportional term, Kp and an Integral term, $\mathrm{Ki}$ that reacts to the error signal in the system. Various authors in the literature suggest that higher bandwidth is achieved by higher proportional gain while the large integral gain facilitates the control strategy to avoid lower frequency hindrances [16]. Schematic diagram of the PI controller as shown in Figure 3.

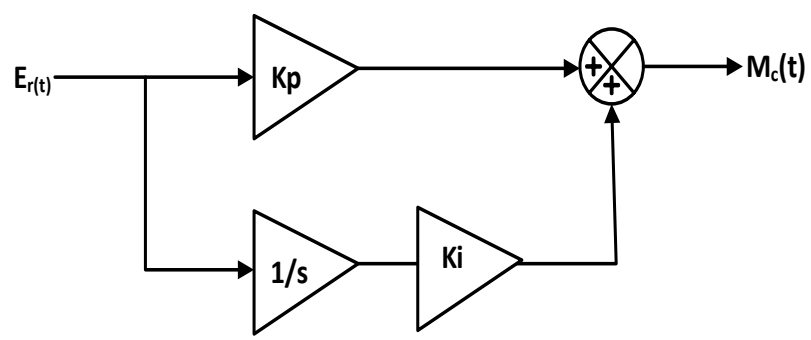

Figure 4. Schematic diagram of the PI controller

The relation involving the input signal (Error signal) and output signal (control signal) of the PI control mechanism can be demonstrated by the (30) and its Laplace form can be shown by taking its Laplace transformation.

$$
\begin{aligned}
& m_{c}(t)=K_{p} E_{r}(t)+K_{i} \int E_{r}(t) d t \\
& m_{c}(t)=K_{p} E_{r}(t)+K_{i} \frac{E_{r}(s)}{s} \\
& m_{c}(t)=E_{r}(t)\left[K_{p}+\frac{K_{i}}{s}\right]
\end{aligned}
$$


For obtaining the transfer function of the PI controller, the (32) is arranged to obtain the transfer function in the Laplace domain as shown (33).

$$
G_{P I}(s)=\frac{m_{c}(s)}{E_{r}(s)}=\frac{K_{p} s+K_{i}}{s}
$$

\section{ADAPTIVE GENETIC ALGORITHM BASED PI CONTROLLER}

In Genetic Algorithm, a population of strings, also called chromosomes encode an individual solution for optimizing the result, evolves toward certain more efficient solutions. Noticeably, solutions are signified in binary form as the strings of zeros and ones [17]. In the GA process, the evolution is started from a population where the individuals are generated randomly and the generation continues till stopping criteria. Here, in all iteration the fitness value of each population is obtained based on which the individuals with higher fitness are selected to provide a solution. Further, the selected populations are altered by performing reproduction and mutation to generate a new generation having better fitness and proximity to the optimal solution. The newly obtained population is then processed in the next iteration to achieve a better solution than the previous once and this process continues till the stopping criterion is obtained. It might continue iterating until the error becomes minimal by maintaining generation and load demands equal.

\section{SIMULATION RESULTS \& DISCUSSION}

In this work, a grid linked solar photovoltaic system is designed where electrical power is given to inverter at $1450 \mathrm{~V}$ DC and is converted to the 3 phase AC power which is further being fed to the grid. The grid phase to ground voltage is considered to be $340 \mathrm{~V}$ ( $415 \mathrm{~V}$ approx. line to line). The power injection to the grid can be controlled by controlling the three parameters i.e. Dc Link voltage, Direct Axis current and quadrature axis current. These three parameters are controlled using three PI controllers which are tuned in this work.

The total simulation runs for $0.35 \mathrm{~s}$. At $0.025 \mathrm{~s}$, the inverter is de-blocked and it starts injecting current in the grid. The time delay of $0.025 \mathrm{~s}$ is considered because after this instant, the DC link capacitor starts charging and maintains the dc voltage $1450 \mathrm{~V}$ as observed in Figure 4(a). When the DC voltage starts building, the active power being fed to the grid starts rising up to steady state value as shown in Figure 4(b) and reaches to the value of approx. 93KW.The current injected by the inverter to the grid is shown in Figure 5(a) and Figure 5 (b) respectively by using two approaches (PI controller and GA optimized PI controller based inverter control strategy). At $0.1 \mathrm{~s}$ the reactive power is switched from 0 to $50 \mathrm{KW}$ and which can be observed in the current waveforms in Figures 6.
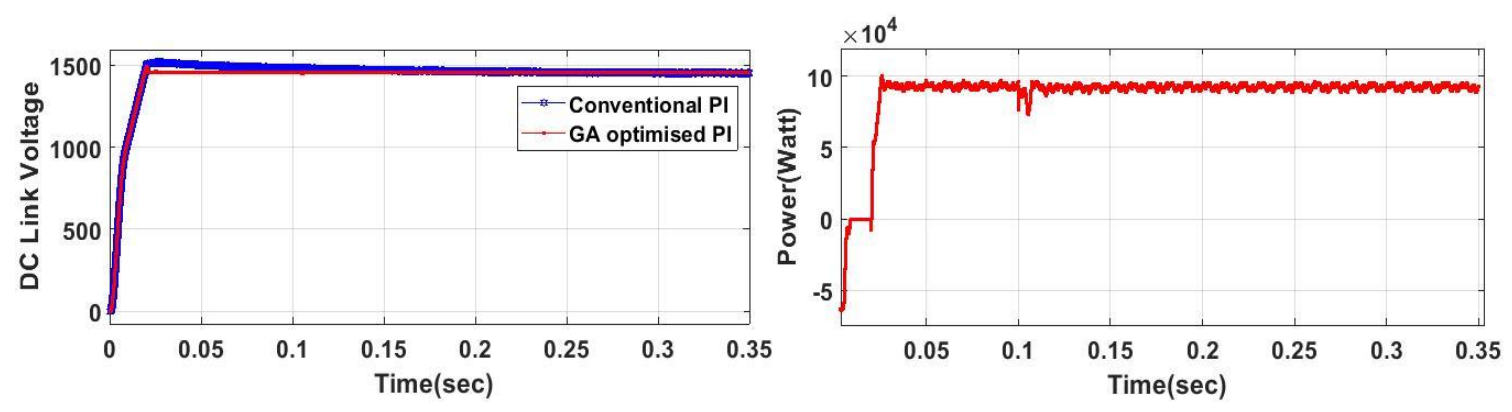

Figure 4. (a) DC Link Voltage for Conventional PI controller v/s GA optimized controller (b)Power delivered to the Grid

The dc link voltage while using the conventional PI controller takes more time to settle to a level of $1450 \mathrm{~V}$ as compared to when GA optimized PI controller is used. 


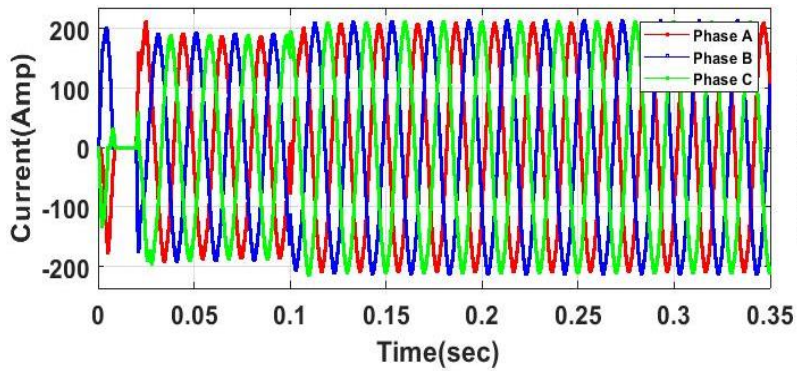

(a)

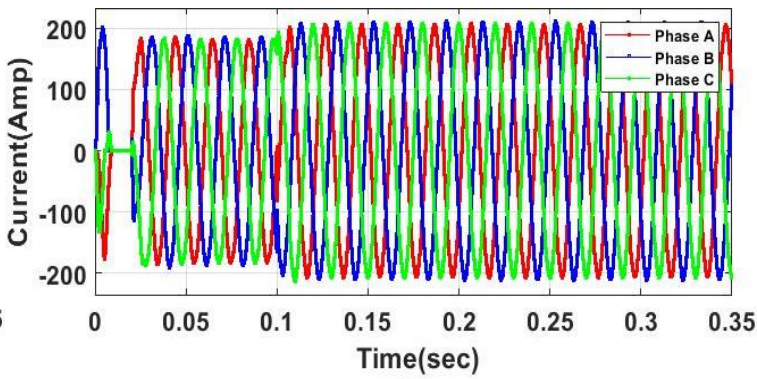

(b)

Figure 5. Three phase current waveform for conventional PI controller (b) Three phase current waveform for GA optimized PI controller

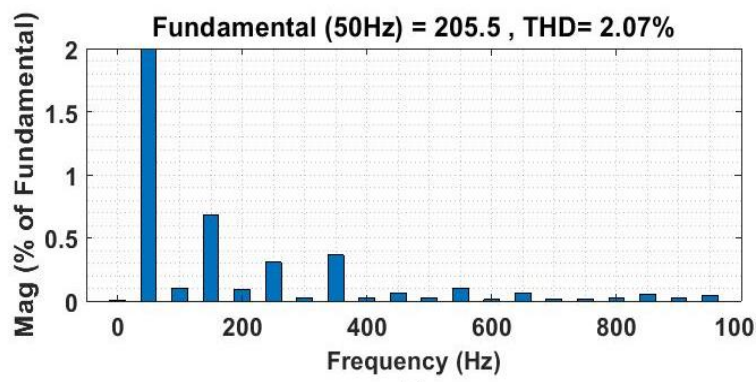

(a)

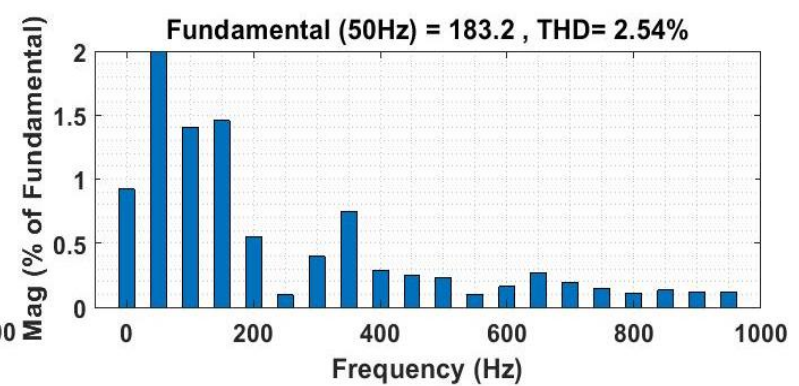

(b)

Figure 6. (a) THD levels for current injected into the grid by using conventional PI controller

(b) THD levels for current injected into the grid by using GA optimized PI controller

The total harmonic distortion is observed to be reduced as shown in Figure 6(b) as compared to in Figure 6(a). It shows that the grid current being injected into the grid comprises a harmonic level of $2.07 \%$ which is very less as compared to $2.59 \%$ when the conventional PI controller was implemented.

\section{CONCLUSION}

A $100 \mathrm{KW}$ grid-connected system has been designed by employing an inverter control strategy for the power quality improvement in a PV connected utility grid. The MPPT method helps in extracting maximum power from the photovoltaic array and the boost converter boost the DC voltage to the desired specifications. The comparison between the conventional PI controller and GA optimized PI controller used in inverter control strategy has been shown and the power quality has been observed to be improving which can be seen in the FFT analysis of the current waveform injected into the grid.

\section{REFERENCES}

[1] Kadri R, Gaubert JP, Champenois Gerard,“An Improved Maximum Power Point Tracking for Photovoltaic GridConnected Inverter based on Voltage-Oriented Control”, IEEE Trans Ind. Electron 2011;58(1):66-74.

[2] Rey-Boue AB, Garci'a-Valverde R, Ruz-Vila F, Torrelo-Ponce JM,“An Integrative Approach to the Design Methodology for 3-Phase Power Conditioners in Photovoltaic Grid-Connected Systems"Energy Convers Manage 2012;56:80-95.

[3] M. Gupta and R. Kumar, "Detection of Power Quality Disturbances using Symbolic Dynamics," International Conference on Recent Advances and Innovations in Engineering (ICRAIE-2014), Jaipur, 2014, pp. 1-8.

[4] V. B. Savakhande, C. L. Bhattar and P. L. Bhattar, "Voltage-Lift DC-DC Converters for Photovoltaic ApplicationA Review," 2017 International Conference on Data Management, Analytics and Innovation (ICDMAI), Pune, 2017, pp. 172-176.

[5] A. Lavanya, J. D. Navamani, K. Vijayakumar and R. Rakesh, "Multi-Input DC-DC Converter Topologies-A Review," 2016 International Conference on Electrical, Electronics, and Optimization Techniques (ICEEOT), Chennai, 2016, pp. 2230-2233. 
[6] S. M. Akbar and A. Hasan, "Review of High Voltage DC/DC Modular Multilevel Converters," 2018 15th International Conference on Smart Cities: Improving Quality of Life Using ICT \& IoT (HONET-ICT), Islamabad, 2018, pp. 46-50.

[7] B. Yang, W. Li, Y. Zhao and X. He, "Design and Analysis of a Grid-Connected Photovoltaic Power System," in IEEE Transactions on Power Electronics, vol. 25, no. 4, pp. 992-1000, April 2010. doi: 10.1109/TPEL.2009.2036432.

[8] S. L. Prakash, M. Arutchelvi and S. S. Sharon, "Simulation and Performance Analysis of MPPT for Single Stage PV Grid Connected System," 2015 IEEE 9th International Conference on Intelligent Systems and Control (ISCO), Coimbatore, 2015, pp. 1-6.

[9] R. Errouissi, A. Al-Durra and S. M. Muyeen, "A Robust Continuous-Time MPC of a DC-DC Boost Converter Interfaced with a Grid-Connected Photovoltaic System," in IEEE Journal of Photovoltaics, vol. 6, no. 6, pp. 1619-1629, Nov. 2016.

[10] S. Vighetti, J. Ferrieux and Y. Lembeye, "Optimization and Design of a Cascaded DC/DC Converter Devoted to Grid-Connected Photovoltaic Systems," in IEEE Transactions on Power Electronics, vol. 27, no. 4, pp. 2018-2027, April 2012.

[11] M. Killi and S. Samanta, "Modified Perturb and Observe MPPT Algorithm for Drift Avoidance in Photovoltaic Systems," in IEEE Transactions on Industrial Electronics, vol. 62, no. 9, pp. 5549-5559, Sept. 2015.

[12] M. Liu, J. Huang, Y. Dong and H. Li, "Steady-State Control Performance Modeling and Simulation Analysis for Grid-Connected PV Inverter," 2016 China International Conference on Electricity Distribution (CICED), Xi'an, 2016, pp. 1-4.

[13] Wu Jianhua, Zhong Jing, Li Longfei, Tang Cong and Yu Le, "Predictive Control based on Analytic Model for PV Grid-Connected Inverters," 2012 24th Chinese Control and Decision Conference (CCDC), Taiyuan, 2012, pp. 4295-4299.

[14] E. Afshari, G. R. Moradi, Y. Yang, B. Farhangi and S. Farhangi, "A Review on Current Reference Calculation of Three-Phase Grid-Connected PV Converters under Grid Faults," 2017 IEEE Power and Energy Conference at Illinois (PECI), Champaign, IL, 2017, pp. 1-7.

[15] B. Pal, P. K. Sahu and S. Mohapatra, "A Review on Feedback Current Control Techniques of Grid-Connected PV Inverter System with LCL Filter," 2018 Technologies for Smart-City Energy Security and Power (ICSESP), Bhubaneswar, 2018, pp. 1-6.

[16] G. Ellis, "Control System Design Guide - A Practical Guide": Elsevier, 2004.

[17] D. C. Meena and A. Devanshu, "Genetic Algorithm Tuned PID Controller for Process Control," 2017 International Conference on Inventive Systems and Control (ICISC), Coimbatore, 2017, pp.1-6.doi: 10.1109/ICISC.2017.8068639. 